\title{
The Hong Kong Jockey Club: Driving Sustainability and Riding High Together - A Case Study
}

\author{
Yihong $\mathrm{YaO}^{1}$, Dongya $\mathrm{Li}^{1}$
}

\begin{abstract}
In recent years, sustainability has become a popular topic for both business and society. There is little dispute that companies and organizations have increasingly paid attention to social and environmental issues, and thus sustainability has come under the spotlight. However, The Hong Kong Jockey Club ("HKJC" or "the Club"), the largest single taxpayer and non-government charitable donor in Hong Kong, has been paying attention to environmental and social issues for decades although its "sustainability efforts" were not given a label for most of that period. The year of 2009 was a milestone of the HKJC's sustainability endeavors as in this year the HKJC formed its first Sustainability Committee, raising sustainability to the strategic level within the Club. The first sustainability report of HKJC was released in 2011, making the HKJC's dialogue with the community, also within the Club, transparent. In 2014, the Club introduced Supplier Sustainability Guidelines, aiming to increase the sustainability standards of the Club's business partners, and in turn, of all local businesses.

This case depicts how HKJC achieved sustainability through its endeavors in the environmental, social, and governance (ESG) areas, thus contributing to the community and enabling a better future for its stakeholders and for society as a whole. This case also discusses the evolution of the HKJC's sustainability governance structure and strategy, the progress of HKJC's sustainability practices from 2009 to 2016, and HKJC's sustainability challenges.
\end{abstract}

Keywords: Hong Kong Jockey Club, sustainability governance, sustainability practice, sustainability innovation, carbon footprint, supplier sustainability, stakeholder engagement, case study

\section{Introduction}

In recent years, sustainability has become a popular topic in both business and society. Business sustainability is defined as the status of "businesses that can survive shocks because they are intimately connected to healthy economic, social and environmental systems; they create economic value and contribute to healthy ecosystems and strong communities" (Financial Times Lexicon, 2016). The global economy, the environment and political institutions have been experiencing quick structural changes, forcing businesses to change their strategies from one for short-term profitability to the other for long-term sustainability (Werbach, 2009). Companies and organizations have increasingly paid attention to social and environmental issues, and thus sustainability is placed under the spotlight. Environmental issues bring pressures for senior executives when they make decisions and require them to rethink how they could reach a balance between business growth and environmental concerns, and even how they could capitalize the opportunities and benefits from sustainability practices and innovations 
(Lampikoski et al., 2014). The benefits of sustainability in business are clear. Sustainability practices allow companies to create values through eco-efficiency, green innovations, revolution with new technology, andexternal partnership of sustainability (Lampikoski et al., 2014). Sustainable operations generate impacts on the triple bottom line: environmental, social and economic performances of companies (Gimenez, 2012). Addressing sustainability generates positive impacts on companies, including image and brand improvement, cost saving, competitive advantage, employee satisfaction, product and service innovation, business innovation, effective risk management, and stakeholder relation enhancement (Berns et al., 2009). In addition, sustainability would affect business and change management (Hopkins, 2009). To make a company's sustainability strategy sustainable, the company should create a sustainability-focused culture within the organization (Galpin, 2013). Moreover, companies and organizations, when working with their supplier partners, must consider not only overall supply chain efficiency, but also social, economic and environmental factors, thus upstreaming sustainability of supply chain management practices (Azevedo, 2012).

This case depicts how The Hong Kong Jockey Club ("HKJC" or "the Club") achieved sustainability through endeavors in the environmental, social, and governance (ESG) areas, thus contributing to the community and enabling a better future for its stakeholders and for the whole society. This case also discusses the evolution of HKJC's sustainability governance structure and strategy, the progress of HKJC's sustainability practices from 2009 to 2016, and HKJC's sustainability challenges.

\section{Practical Questions Related to Sustainability of The Hong Kong Jockey Club}

Appointed as the first Executive Manager, Sustainability, Shirlee Algire joined the Club in 2015. Immediately after assuming the position, Algire was tasked to lead a sustainability team and coordinate with major operational divisions of the Club to put the Club's sustainability vision and strategy into practice. However, the tasks seemed to be much more complex than expected. On the one hand, the Club's sustainability efforts were not only limited to day-to-day internal operations of the Club, but also in recent years more frequently referred to external parties such as suppliers, NGOs, and the local community. On the other hand, the Club must make clear what sustainability achievements must be made by June 2017 and make sure that the Club's sustainability best practices could reach a higher standard. What sustainability innovation could be made? How HKJC could further enhance supplier sustainability that the Club newly introduced in 2014? Should the organizational structure of the Club related to sustainability be changed?

\section{Background of The Hong Kong Jockey Club}

Unlike casino or companies in gambling industry, HKJC was a local sporting entertainment provider. The Club was a major contributor in the community. Unlike forprofit businesses that extracted as much economic value as possible, HKJC's business provided right services to Hong Kong people and met the requirements of the society. 
Each year, through tax contributions and donations, the Club gave back around $70 \%$ of its revenue to the society (HKJC, 2016a).

Founded in 1884 as an amateur horseracing club and changed to a professional organization in 1971, the Club now ranked as the largest single taxpayer and nongovernment charitable donor in Hong Kong (HKJC, 2015). The Club possessed a notfor-profit business model without shareholders, a model that differed from that of other business organizations and made the Club admired worldwide. Under this not-for-profit business model, the Club earned revenue from racing, betting, and sporting entertainment; after deducting dividends, prize money, taxes, operating costs, and facility investments, the Club, through The Hong Kong Jockey Club Charities Trust, donated the remaining money to charitable and community projects (HKJC, 2016). In the 2014/15 fiscal year, the Club contributed nearly HK\$20 billion betting duties and taxes; and from July 2013 to June 2015, The Hong Kong Jockey Club Charities Trust donated almost HK\$7.5 billion to hundreds of charitable and community projects (HKJC, 2016). ${ }^{1}$

\section{Sustainability at the Club: An Overview}

The Club had triple bottom lines that related to value creation, and it must consider environmental impact, economic impact and the community when doing businesses (HKJC, 2016a). In fact, during past years, HKJC has made achievements that were far beyond legal requirements on environment. It would like to become a leader of sustainability and set examples for other charities and community benefactors in Hong Kong; it communicated its sustainability best practices and hoped other organizations could copy them (HKJC, 2016a).

Focusing on maintaining value and sustaining an organization, sustainability was a new concept. However, HKJC has been paying attention to environmental and social issues for decades although its "sustainability efforts" were not given a label for most of that period. The year of 2009 was a milestone of HKJC's sustainability endeavors as in this year HKJC formed its first Sustainability Committee, raising sustainability to the strategic level within the Club. The first sustainability report of HKJC was released in 2011, making the HKJC's dialogue with the community, also within the Club, transparent.

The Club conceived a long-standing sustainability vision (HKJC, 2015): to embed sustainability into the culture and major processes of the Club; to enhance public awareness of sustainability via its sphere of influence; and to be a catalyst in driving Hong Kong towards a sustainable future.

\subsection{The Evolvement of Sustainability Governance}

HKJC's core sustainability initiatives were derived from day-to-day operations, and thus these initiatives were highly integrated with its business; HKJC's Sustainability Committee looked at what the organization was doing and facilitated sustainability within and without the organization (HKJC, 2016a).

In the same year at the birth of the Club's sustainability vision in 2009 , the organizational structure of the Club became one of green governance, a structure that supported the

\footnotetext{
${ }^{1}$ The fiscal year of the HKJC began on July 1 and ended on June 30 each year.
} 
basic framework of the sustainability efforts of the Club. At the strategic level, the CEO and the Board of Management received direction from the governing Board of Stewards, oversaw the sustainability strategy, and then reported the implementation of sustainability strategy to the Board (HKJC, 2011). At the management level, the Director of Human Resources and Sustainability was responsible for the day-to-day management of the sustainability strategy, and a sustainability team supported the director's work (HKJC, 2011). At the operational level, the Environmental Management Committee (EMC), consisted of senior representatives from major operational divisions of the Club, was responsible for driving and implementing the environmental policy of the Club; this committee coordinated strategy, monitored progress, held quarterly meetings and made policy recommendations to the Board of Management (HKJC, 2011). This committee not only facilitated the integration of environmental practices into the day-to-day operations of the Club by urging employees to do so, but also encouraged the Club's business partners and suppliers to perform at the same level of environmental practices, thus extending the remit of the committee far beyond the Club (HKJC, 2011) [see Figure $1]$.
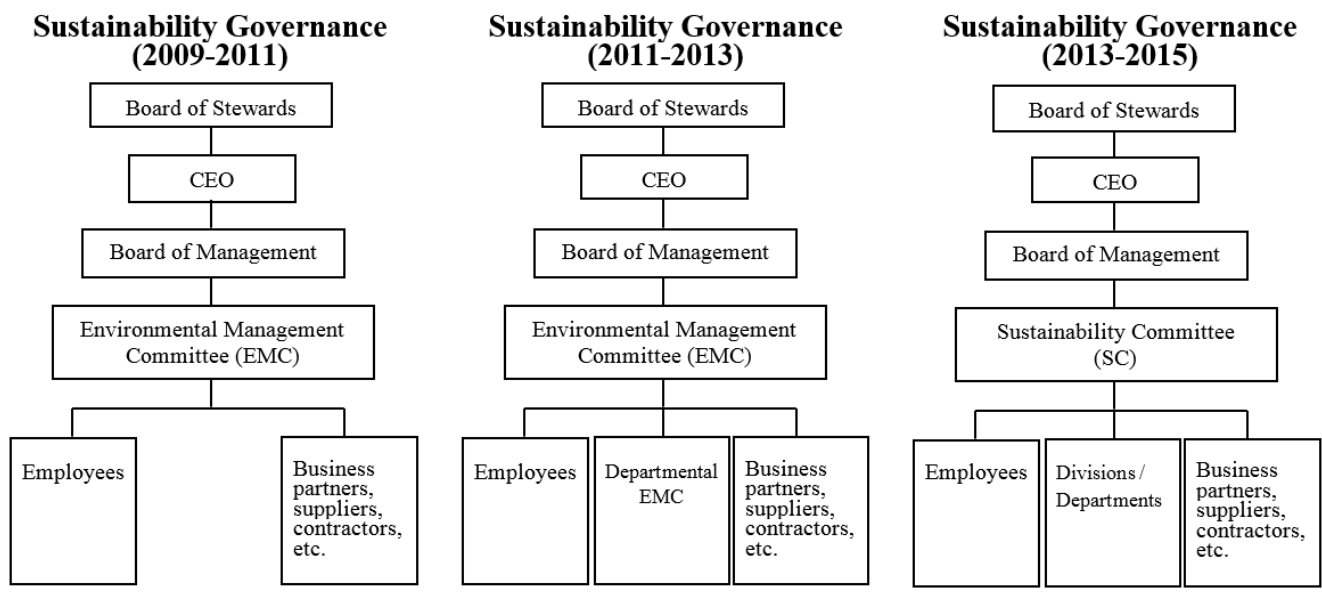

Figure 1: HKJC's Sustainability Governance. Source: The Hong Kong Jockey Club.

In 2011, the Club updated the governance structure of sustainability by adding an Environmental Management Committee (EMC) at departmental level. In 2014, the Club realigned sustainability division from under the human resource department to under the direction of Executive Director, IT \& Sustainability, established the Sustainability Committee (SC), and appointed a new Executive Manager, Sustainability. The replacement of the Environmental Management Committee with Sustainability Committee meant a new era of the Club's sustainability endeavors. At the operational level, the Club spelled out its sustainability strategy in a variety of green policies and guidelines and continuously reviewed and renewed them (HKJC, 2015). The newly established Sustainability Committee, consisted of members from various operational divisions of the Club, oversaw the sustainability position, policies, and practices of the Club (HKJC, 2015). In addition, individual divisions were responsible for vesting 
environmental compliance that aligned with its responsibility in its specific functional area (HKJC, 2015).

\subsection{Policies and Guidelines on Sustainability}

The Club looked at widely-adopted international best practices and global standards; it looked at what large multinational organizations were doing, made benchmark, and found out what it could learn from them (HKJC, 2016a).

In 2009, the Club established a clear environmental policy. This policy covered environmental considerations in operations, compliance with legal requirements, employee training and education, community support on environmental issues, and the requirement for business partners to act at the same level of environmental best practices (HKJC, 2011). In the 2009/11 fiscal year, a number of concrete policies and guidelines were adopted in the Club such as Green Procurement Guidelines, Green Cleaning Guidelines, Waste Management Policies, Sustainability Framework on Construction and Property Projects, and E-waste Management Guidelines (HKJC, 2011). These policies and guidelines were continually reviewed and updated. For instance, the Green Office Guidelines and Sustainable Event Guidelines were introduced in 2011/12 and the Water Management Guidelines, Water Policy and Supplier Sustainability Guidelines were added in 2014/15. The Sustainability Committee regularly held meetings to review at which level the Club has reached and how well each division of the Club had conformed to these sustainability policies and guidelines [see Table 1].

Table 1: HKJC's Environmental Policies and Guidelines. Source: The Hong Kong Jockey Club. [Name of Policies or Guidelines (Year of Introduction)]

\begin{tabular}{|c|c|}
\hline - Environmental Policy (2009/10) & - Green Procurement Guidelines (2009/10) \\
\hline - Green Cleaning Guidelines (2009/10) & - Waste Management Policies (2009/10) \\
\hline $\begin{array}{l}\text { - Sustainability Framework for Property and } \\
\text { Construction Projects }(2009 / 10)\end{array}$ & - E-waste Management Guidelines (2010/11) \\
\hline $\begin{array}{l}\text { - No Sharks Fin for Corporate Activities } \\
\text { Policies }(2010 / 11)\end{array}$ & - $\mathrm{Su}$ \\
\hline - Green Office Guidelines (2011/12) & - $\mathrm{Su}$ \\
\hline - Corporate Sustainability Policy (2012/13) & - Wa \\
\hline - Water Management Guidelines (2013/14) & - Supplier Sustainability Guidelines (2014/15) \\
\hline
\end{tabular}

\section{Sustainability Practices at the Club: 2009-20112}

Two years after the Club put sustainability on the strategic level, the Club published its first sustainability report (2011) that covered the Club's local operations between July 2009 and June 2011, with 2009/10 as base year and 2010/11 as reporting year. The sustainability team of the Club coordinated data collection from relevant divisions and individuals, and then compiled this report with reference to the Global

\footnotetext{
2 Unless otherwise referenced, this session was prepared mainly according to information obtained in the interview with The Hong Kong Jockey Club on 22 January 2016 and information in the HKJC's "Sustainability Report 2011."
} 
Reporting Initiatives (GRI G3), a report that was in accordance with level C of the GRI reporting framework. As the first trial, GRI indicators were not included in this report as they were not tracked, but the sustainability team created performance targets for major indicators and continued to add the remainders.

\subsection{Managing Its Carbon Footprint}

For a couple of years before 2011, the Club enhanced its efforts on managing the impact of its operations on the environment and made its environmental policies closely aligned with government initiatives. It jointly ran a few environmental programs on the efficient use of energy, air quality assurance, and source separation, thus reducing its local carbon footprint although the Club's business was continuously moving forward.

In 2010, the Club carried out the first carbon audit of its four major properties; and in 2011 it expanded the scope of the audit by conducting Club-wide carbon audits. The result showed that the total carbon footprint (total greenhouse gas emissions) of the Club in 2010/11 reduced to 2,598 tonnes of CO2-e (2.17\%) compared with that in 2009/10 [see Table 2].

Table 2: HKJC’s Carbon Footprint. Source: The Hong Kong Jockey Club.

[Unit: CO2-e in tonnes]

\begin{tabular}{|l|l|l|l|l|l|l|}
\hline & $\mathbf{2 0 1 4 / 1 5}$ & $\mathbf{2 0 1 3 / 1 4}$ & $\mathbf{2 0 1 2 / 1 3}$ & $\mathbf{2 0 1 1 / 1 2}$ & $\mathbf{2 0 1 0 / 1 1}$ & $\mathbf{2 0 0 9 / 1 0}$ \\
\hline Total Carbon Emissions & $\mathbf{1 2 3 , 1 1 6}$ & $\mathbf{1 1 9 , 6 4 3}$ & $\mathbf{1 1 9 , 9 7 2}$ & $\mathbf{1 2 2 , 9 6 5}$ & $\mathbf{1 1 7 , 2 3 1}$ & $\mathbf{1 1 9 , 8 2 9}$ \\
\hline $\begin{array}{l}\text { Indirect emissions from } \\
\text { electricity }\end{array}$ & 114,938 & 112,749 & 113,010 & 115,351 & 109,728 & 113,267 \\
\hline $\begin{array}{l}\text { Fugitive emissions from } \\
\text { refrigerant }\end{array}$ & 4,293 & 2,677 & 2,780 & 3,480 & 3,446 & 2,686 \\
\hline $\begin{array}{l}\text { Direct emissions from } \\
\text { facilities }\end{array}$ & 2,342 & 2,654 & 2,685 & 2,627 & 2,453 & 2,367 \\
\hline $\begin{array}{l}\text { Direct emissions from } \\
\text { transportation }\end{array}$ & 1,016 & 1,030 & 948 & 959 & 1,099 & 1,035 \\
\hline Indirect emissions from gas & 527 & 533 & 549 & 548 & 505 & 474 \\
\hline
\end{tabular}

As electricity contributed to almost 95\% of the Club's greenhouse gas emissions in this reporting period, and thus total carbon footprint, the Club made major efforts to reduce electricity consumption, efforts including attempting to switch its air-conditioning systems from an air-cooled to water-cooled system, replacing all incandescent lamps with energy-efficient fluorescent lamps, and adopting an automatic facility control system and power management system. In addition, as one of the largest technology users in the city, the Club used electronic-based data storage for both internal operations and external customer transactions; it adopted virtual technology to reduce the number of physical servers required and thus reduced electricity consumption. Electricity consumption was reduced from 175.6 million $\mathrm{kWh}$ in $2009 / 10$ to 169.9 million $\mathrm{kWh}$ in 2010/11, a reduction of 5.7 million $\mathrm{kWh}(3.3 \%)$ [see Table 3]. 
Table 3: HKJC’s Electricity Consumption. Source: The Hong Kong Jockey Club. [Unit: million $\mathrm{kWh}$ ]

\begin{tabular}{|l|l|l|l|l|l|l|}
\hline & $\mathbf{2 0 1 4 / 1 5}$ & $\mathbf{2 0 1 3 / 1 4}$ & $\mathbf{2 0 1 2 / 1 3}$ & $\mathbf{2 0 1 1 / 1 2}$ & $\mathbf{2 0 1 0 / 1 1}$ & $\mathbf{2 0 0 9 / 1 0}$ \\
\hline Electricity Consumption & 166.7 & 165.0 & 170.2 & 174.4 & 169.9 & 175.6 \\
\hline
\end{tabular}

The Club also made efforts to conserve resources and source environmentally friendly materials. These efforts were not limited to internal office operations such as stationery paper usage but also covered its business operations. For example, the Club upgraded its traditional betting terminals that used thick tickets. The new betting terminals allowed customers to enter transactions by using a touch-screen and then receive a thin receipt, both reducing betting tickets and paper usage and making recycling possible. Other measures were also adopted including the use of green energy in biodiesel equipment, solar-powered carts and electric cars, and the separation and recycle of office waste and of organic waste disposal in the Club kitchens.

\subsection{People: Waiving the Green Banner}

As one of the largest employers in Hong Kong, the Club provided employees with rewarding careers and creating opportunities for them to contribute to the community. Acting as an equal opportunity employer, the Club reached a 50:50 ratio of male and female employees; females increasingly undertook positions that were traditionally considered jobs for men such as stable assistants. It also organized occupational safety and health workshops, provided a variety of health benefits to employees, and encouraged staff to be life-long learners by providing training programs and sponsored-learning opportunities.

\subsection{Greening Hong Kong}

With its unique not-for-profit business model under which surpluses of the Club went to charitable and community projects, the Club, through its Charity Trust, donated HK $\$ 1,622$ million to more than 100 such projects in 2010/11. Environment-related projects supported by the Club included projects that highlighted air pollution issues and projects that conducted marine conservation. In addition, in August 2010, the Club launched the Jockey Club Environmental Conservation Gallery at the Hong Kong Science Museum, allowing the public to learn and think about green living practices.

\section{Sustainability Practices at the Club: $2011-2013^{3}$}

In 2013, the Club introduced its second sustainability report that covered the Club's operation between July 2011 to June 2013, with 2011/12 as base year and $2012 / 13$ as reporting year. In addition to local matters, this report also covered the Jockey Club Clubhouse at Beijing, China. This report was compiled with reference to the Global Reporting Initiatives (GRI G3.1) and received an application level of B+ in the

\footnotetext{
3 Unless otherwise referenced, this session was prepared mainly according to information obtained in the interview with The Hong Kong Jockey Club on 22 January 2016 and information in the HKJC's "Sustainability Report 2013."
} 
GRI application level check made by an independent third party, the Global Reporting Initiative.

\subsection{Managing Its Carbon Footprint}

Between 2011 and 2013, the Club strengthened and widened the coverage of its environmental efforts; it introduced Green Office Guidelines and launched a web-based sustainability measurement and reporting system (SMRS), a system that covered major facilities in Hong Kong and China and allowed users in operational divisions to input data and monitor progress, making real-time review of the Club's overall environmental performance possible.

During this reporting period, the Club progressively replaced its old air-conditioners and established central chiller plants, installed with new water-cooler chiller part that reduced ozone-depleting potential and ranked in high efficiency class. Although the business activities of the Club were increasing during this period, the environmental efforts were making headway and the result was encouraging. In 2012/13 the total carbon footprint of the club was 119,972 tonnes of CO2-e compared with 122,965 tonnes in 2011/12, representing a reduction of 2,993 tonnes $(2.4 \%)$ [see Table 2].

Spending around $\mathrm{HK} \$ 500$ million, the Club continued to invest in energy-efficient technology, enhance energy management systems, and reduce light spill levels, aiming to decrease the long-term impacts of temperature increase caused by climate change. The Club began to use LED lighting and continued to employ an additional 1,496 virtual servers to optimize efficiency.

The business expansion of the Club required more office space and the Club has been progressively renovating its facilities, a situation that provided opportunities for the Club to adopt sustainable practices and employ environmentally friendly materials and technologies such as natural light, jet hand dryers, and customized ventilation controls. Materials from sustainable sources were used in operations and total consumption was reduced. The Green Procurement Guidelines helped the Club to reach green-purchasing decisions. The Club also actively made sustainability innovations. For example, the Club's marketing team made an "upcycling" innovation by crafting horseshoes into various art pieces, which then became popular souvenir items in its gift shops. The Club's fuel consumption also decreased by 5\% per kilometer from 2011/12 to 2012/13, and $80 \%$ of food waste was collected and recycled in 2013.

During this reporting period, the Club's sustainability had been extended to its Clubhouse in Beijing, where a number of sustainability practices were under way.

\subsection{Working for a Sustainable Future}

With the wide range of the its businesses, the Club provided diverse employment opportunities covering the areas of horse care and training, hospitality, retail, IT, and charity support and administration. Employment extended to almost every district of Hong Kong, including socially disadvantaged regions such as Tin Shui Wai located in the north-western New Territories of Hong Kong, in which the Club's telebet center provided nearly 2,000 job opportunities. The Club endeavored to create a working environment that supported its staff and that allowed its employees to develop their potential. In November 2010, the Club became one of the few employers in Hong Kong 
that provided paternity leave for full-time male employees. To support employees to pursue professional qualifications, in 2011 the Club founded the Jockey Club College that provided job training, self-paced learning, and e-learning. In 2012, the Club established a Safety Management System (SMS) that consolidated all Occupational Safety and Health (OSH) activities within the entire Club; and the Club's Corporate Safety Committee comprising of representatives from divisions of the Club oversaw the system.

\subsection{Greening Hong Kong}

With its wide-range and deep-root involvement in the community, the Club, by working directly or through its Charities Trust, actively promoted sustainability in Hong Kong. In 2012/13, the Club donated HK\$1.95 billion to around 160 charitable and community projects. Environment-related projects supported by the Club included glass bottle recycling project, environment public education campaign, community organic farming campaign, and elderly green living program. The Club also launched its largest heritage conservation project - the restoration of the Central Police Station, an area of 300,000 square feet.

\section{Sustainability Practices at the Club: 2013-2015}

The third sustainability report of the Club was published in 2015. This report covered the Club's operation between July 2013 to June 2015, with 2013/14 as base year and 2014/15 as reporting year. This report was assured by a third party and was in accordance with the core options of the Global Reporting Initiatives (GRI G4.0). It not only covered the Club's local operations, but also included information on the Club's joint ventures outside Hong Kong. This report focused on activities that were material to both the Club and its stakeholders.

\subsection{Managing its Carbon Footprint}

Between 2013 and 2015, the Club considered the reduction of its environmental impact and the community-wide solutions for sustainability issues core elements of its sustainability strategy. In line with this strategy, the Club focused on reducing carbon emissions and waste materials, and on enhancing energy efficiency and recycling waste materials, thus demonstrating its responsibility and care for environment at all facilities of the Club's operation. Despite facing challenges and difficulties of supporting an expanding business, the Club made positive progress.

In 2014/15, the total carbon footprint of the Club reached a historical high since 2009, which was 123,116 tonnes of CO2-e [see Table 2]. The Club explained that the minor increase was caused by the growing scale of the Club's business and operations. The Club realized this issue and continuously explored ways to improve these figures. The Club also made long-term investments to alleviate climate change and enhance biodiversity. For example, during this reporting period, the Club invested in two

\footnotetext{
${ }_{4}^{4}$ Unless otherwise referenced, this session was prepared mainly according to information obtained in the interview with The Hong Kong Jockey Club on 22 January 2016 and information in the HKJC's "Sustainability Report 2015."
} 
afforestation projects at Guangdong, China, which was the source of Dongjiang River that provided fresh water for the day-to-day lives of Hong Kong citizens.

The Club made a huge investment in technology and operations optimization and established a comprehensive sustainability strategy for both new and existing facilities, aiming to achieve energy and resource efficiency. Good practices included efficient information architecture that made more electronic services available, energy-efficient lighting and cooling systems, building management system, and energy-efficient floodlighting. By June 2015, electricity consumption had been reduced by almost 9 million $\mathrm{kWh}(5.1 \%)$ since 2009/10 [see Table 3].

During this reporting period, the Club enhanced its resource management under the principle of "use wisely, waste less." It set targets for the use of materials and the recycling of waste, aiming to reduce life-cycle impacts on resources and trying to extract more values from them. In practice, the Club used recycled or FSC-sourced paper, replaced 1,350 individual printers with 443 shared ones, donated surplus food to welfare organizations, and recycled glass bottles into eco-bricks. The scope of resource management was further expanded and covered eco-friendly packaging. More gift items were made from waste materials. The Club also recycled 11,447 liters of cooking oil and converted it into biodiesel. The Club closely monitored the fuel performance of its vehicles to seek further improvement; at the same time a centralized system was in use to increase the efficient use of cars by sharing.

The Club always kept its systems up-to-date and continuously made innovations in businesses, definitely including sustainability aspects. By doing so, it created competitive advantages. A sustainability innovation was made for the prestigious Asian Racing Conference held in May 2014, in which each delegate was provided with a tablet computer, with which delegates could read presentation documents pre-loaded into the tablet and make convenient notes. This significantly avoided paper wastage used in such conferences and received much appreciation.

With the introduction of a water policy and water management guidelines in 2014 and of a Club-wide water audit, the Club revised work practices and updated instructions to carefully manage water usage. Although the water consumption of the Club in 2014/15 increased around $8 \%$ since 2011/12 caused by the transformation from electricity cooling system to water-cooled chiller plants, water consumption in 2014/15 decreased more than 1\% since 2013/14 [see Table 4].

Table 4: HKJC's Water Consumption (Municipal Source). Source: The Hong Kong Jockey Club. [Unit: million $\mathrm{m}^{3}$ ]

\begin{tabular}{|l|l|l|l|l|l|l|}
\hline & $2014 / 15$ & $2013 / 14$ & $2012 / 13$ & $2011 / 12$ & $2010 / 11$ & $2009 / 10$ \\
\hline $\begin{array}{l}\text { Water Consumption- } \\
\text { Municipal Source }\end{array}$ & 1.73 & 1.75 & 1.70 & 1.60 & N.A & N.A. \\
\hline
\end{tabular}

The Club also improved its green property management, which considered construction waste management, building performance, emissions control, performance improvement, indoor environmental quality improvement, and energy conservation.

Making a further step, during 2014/15, the Club, with reference to the Convention on Biological Diversity set by the United Nations, conducted a biodiversity study of its three 
major facilities. The study found out that the Club's operations made no significant negative impacts on habitats and biodiversity.

\subsection{Caring for Employees}

As one of Hong Kong's largest employers, the Club committed to being a caring and responsible employer. The Club thus made efforts on people development, guaranteed occupational safety and health, organized corporate wellness programs, and advanced diversity in the workplace. In 2014/15, each full-time employee in Hong Kong and each part-time employee in Hong Kong received an average of 42.1 and 10.4 hours of training, and thus the total yearly training hours of the Club reached more than 420,000. In this reporting period, the Occupational Safety and Health (OSH) became more systematic under which Corporate Safety Committee reported directed to the Board of Management and oversaw the implementation of safety policy in workplace. The Club's latest initiative on corporate wellness, the Happy-at-work@HKJC program, was launched to help employees to effectively manage stress, thus achieving health and balanced life.

\subsection{Towards a Better Future}

The Club made clear directions for the coming three to five years that it would primary support for three areas in Hong Kong: youth development, elderly welfare, and sport. To understand the actual needs of charitable and social groups, the Club conducted a study covering around 1,000 NGOs. The study found that many small-tomedium organizations did not lack operational capital but needed support in operational areas such as human resources, management, and technology. The proactive initiative under the Dongxiang afforestation project launched in 2014, HKJC Forest, covered an area of 4,000 $\mathrm{mu}$ and the planting of more than 350,000 trees. In this reporting period, the Club supported a number of environmental projects such as food rescue and hot meal assistance program, nature and man in one campaign, and project zero that taught young people how to reduce or offset carbon footprint.

\section{Engaging People and External Parties ${ }^{5}$}

\subsection{Employees}

To implement its sustainability strategy, HKJC needed not only money but also resources. Resources had value, and one key resource was people. When the Club had people engaged, it would make sustainability actions alive (HKJC, 2016a).

The Club considered employee engagement in its sustainability endeavors a key factor for the success of these endeavors, allowing its enthusiastic staff perform their expertise for Hong Kong. The CARE@HKJC Volunteer Team consisting of almost 1,000 employees was established in 2005; the volunteer team cooperated with more than 100 organizations and helped the needy and the disadvantaged groups in the city. In 2010,

\footnotetext{
5 Unless otherwise referenced, this session was prepared mainly according to information obtained in the interview with The Hong Kong Jockey Club on 22 January 2016 and information in the HKJC's "Sustainability Reports 2011, 2013 and 2015."
} 
the Club launched Green Action Program, aiming to promote sustainability and increasing the awareness of sustainability among the Club's staff and their families. Between 2013 and 2015, more than 3,000 employees, their family members and their friends joined more than 30 campaigns such as e-waste recycling, coastal clean-up, ecoenzyme workshop, and a green movie night.

\subsection{Communities and NGOs}

Aiming to enhance the community's awareness of the Club's support for sustainability and service to the community, the Club forged sustainability partnerships by supporting a variety of local sustainability initiatives proposed by NGOs in Hong Kong, such as Caritas Hong Kong, WWF-HK, Green Council, Friends of the Earth, and The Conservation Association. These partnerships significantly enhanced the scale and depth of the Club's sustainability efforts.

\subsection{Suppliers}

Now many businesses had sustainability strategies, and this was also true for HKJC's supply chain partners. The Club would like to create the power of influence and leverage its advantage in sustainability. Over the past three years, it has been seeking where its impact of sustainability was and trying to establish a network for sustainability, thus contributing to the promotion of sustainability in Hong Kong (HKJC, 2016a).

Data showed that in $2014 / 15$, more than $95 \%$ of the Club's direct spending (total annual expenditure) was spent locally. The Club had almost 3,900 suppliers providing food and beverage, construction and materials, and clearing and security services, $90 \%$ of them local. The introduction of Supplier Sustainability Guidelines in 2014 required the Club's suppliers to support and contribute to the Club's sustainability objectives, aiming to increase the sustainability standards of the Club's business partners, and in turn, of the entire local businesses. The guidelines covered five major areas: Ethical Business Practices, Best Employment Practices in the Workplace, Environmental Management Systems, Occupational Safety and Health, and Supply Chain Management [see Figure 2]. In 2015 the Club began to conduct a survey to understand its suppliers' compatibility with the guidelines and formulated three-year to five-year perspectives concerning how to work with suppliers to address ethics, employment, environment, and occupational safety and health issues.

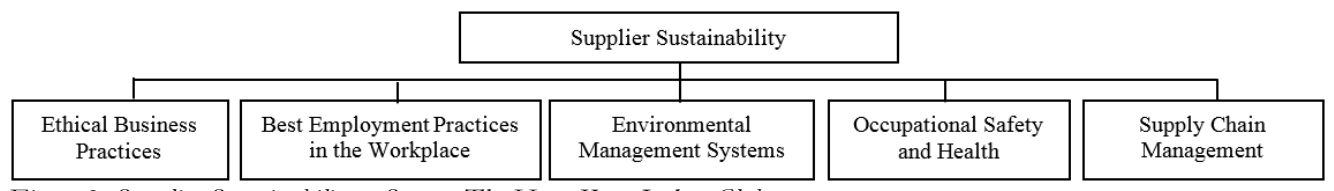

Figure 2: Supplier Sustainability. Source: The Hong Kong Jockey Club.

\section{Challenges}

The Club was a well-known organization in Hong Kong with an excellent reputation accumulated in the past 130 years. When it designed and implemented its 
sustainability initiatives, it must make sure that these initiatives could be accepted by the community and benefit the community (HKJC, 2016a).

In the past 130 years, the Club has evolved into a huge organization with a complex structure. Unlike many other small organizations that could deliver a proposal in one year, the Club could not do so, as it must understand the complexity of the whole organization and consider numerous factors when making any decision. In addition, the Club might need to change its management structure of sustainability, system technology, and policies to adapt to new operational environments and its expanding businesses. Moreover, the cultivation of people's awareness on sustainability and the change of their behaviors, such as using hand dryers instead of paper, were much more difficult than conducting sustainability best practices alone. Many people knew little about sustainability or might be confused about it. When they were given basic frames, they would then think and generate a perception, a perception that would affect their future behaviors (HKJC, 2016a).

Many businesses in Hong Kong, particularly small businesses, may not want to start sustainability plans if they did not realize and receive the direct benefit of such plans. For example, small businesses may not understand much about energy efficiency. A few small businesses may invest environmental-friendly air-conditioners aiming to save energy, and thus cost; but when later the small business found that it did not get any cost saving, what would happen? It would become very frustrated. So there were gaps among perception, expectation and outcome. HKJC needed to show how it has been effectively filling these gaps by systematic management, monitoring and regular check. Thus, share its experiences in sustainability management (HKJC, 2016a).

\section{Ways Ahead}

There were many efforts that HKJC could do, and the sustainability reports did not cover everything that the Club was actually doing. The Club has to understand the impacts of various sustainability issues such as energy saving, water management, and waste recycling, and then it will know how it can do better. Particularly, long-term efficient energy use was the primary issue for the Club, and it would continue to improve this. In addition, it would more actively connect people, identify audience groups and provide trainings through formal or informal activities. The ways ahead were not straight forward but very difficult because on the one hand the Club must continuously reach higher and on the other hand it faced unforeseeable challenges (HKJC, 2016a).

The Club's business volume had continuously increased, and so had the uncertainty. This posed huge challenges for the Club's sustainability plans and implementation. The Club also expanded, developed or renovated its facilities. The increasing business volume and organizational expansion brought many opportunities for achieving sustainability. In addition, more and more customers were using e-services that consumed less paper but more electronic devices and electricity than traditional services did, requiring the Club to make sustainability innovation that responded to this new technology and change in customer behavior. 


\section{Conclusion}

This case explores practical questions related to sustainability of the Club, the origin of the Club's sustainability strategy, the evolvement of sustainability governance within the Club, and the Club's policies and guidelines on sustainability. A review of sustainability practices of the Club from 2009 to 2016 is conducted, followed by the discussion on how the Club engaged people and external parties on sustainability endeavors, its sustainability challenges and future directions. Our case study is one of the first studies that explores the approach of HKJC to sustainability in terms of strategy and endeavors, achievements, innovation, as well as perspectives, and thus makes significant contributions to literature and practices in sustainability. On the one hand, the case study permits companies and organizations to refer to HKJC's experience in designing their own sustainability strategies and implementation plans; on the other hand, this case allows suppliers to evaluate how they could better acknowledge and embrace sustainability objectives of their target client companies that enforce supplier sustainability guidelines.

\section{Acknowledgement}

This paper was fully supported by a grant from the Research Grants Council of the Hong Kong Special Administrative Region, China (UGC/IDS12/14).

\section{References}

Azevedo, S., Carvalho, H., Duarte, S., \& Cruz-Machado, v. (2012). Influence of Green and Lean Upstream Supply Chain Management Practices on Business Sustainability. IEEE Transactions on Engineering Management, 59(4), 753-765.

Berns, M., Townend, A., Khayat, Z., Balagopal, B., Reeves, M., Hopkins, M., \& Kruschwitz, N. (2009). Sustainability and Competitive Advantage. MIT Sloan Management Review, 51(1), 19-26.

Financial Times Lexicon. (2016). Definition of business sustainability. Retrieved from http://lexicon.ft.com/Term?term=business-sustainability

Galpin, T., Whittington, J.L., \& Bell G. (2013). Is Your Sustainability Strategy Sustainable? Creating A Culture of Sustainability? Corporate Governance, 15(1), 1-18.

Gimenez, C., Sierra, V., \& Rodon, J. (2012). Sustainable Operations: Their Impact on the Triple Bottom Line. International Journal of Production Economics, 140(1), 149-159.

HKJC. (2011). The Hong Kong Jockey Club Sustainability Report 2011.

HKJC. (2013). The Hong Kong Jockey Club Sustainability Report 2013.

HKJC. (2015). The Hong Kong Jockey Club Sustainability Report 2015.

HKJC. (2016). About HKJC. Retrieved from http://corporate.hkjc.com/corporate/english/index.aspx

HKJC. (2016a). Interview with The Hong Kong Jockey Club on 22 January 2016. Centennial College, The University of Hong Kong.

Hopkins, M. (2009). Eight Reasons that Sustainability Will Change Management. MIT Sloan Management Review, 51(1), 27-30.

Lampikoski, T., Westerlund, M., Rajala, R., \& Moller, K. (2014). Green Innovation Games: Value-Creation Strategies for Corporate Sustainability. California Management Review, 57(1), 88-116.

Werbach, A. (2009). Strategy for Sustainability: A Business Manifesto. Harvard Business Press. 